\title{
Sports Sentiment and Stock Returns: The Bombay Stock Exchange
}

\author{
Francisca M. Beer*, Frank Lin \\ California State University, San Bernardino, USA
}

$\begin{array}{ll}\text { Article history: } & \\ \text { Received: } & 02 / 07 / 2018 \\ \text { Revised: } & 14 / 12 / 2018 \\ \text { Accepted: } & 28 / 01 / 2019 \\ \text { Published: } & 11 / 03 / 2019\end{array}$

\begin{abstract}
Problem/Relevance: This study is motivated by psychological evidence of a strong connection between sporting event outcomes and mood. To evaluate this connection, we analyze the Indian stock market reaction to sudden changes in investors' mood captured by India's cricket results. By focusing on a rarely studied mood variable and a very infrequently studied stock exchange, this study adds to our understanding of the association between sporting event outcomes and mood.
\end{abstract}

Research Objective/Questions: In this study, we investigate the impact of cricket wins and losses on the Bombay Stock Exchange. We hypothesize that cricket wins or losses will drive investors' mood substantially and unambiguously so that the game outcomes will be powerful enough to impact asset prices. We also evaluate the hypothesis that losses are psychologically more powerful than wins.

Methodology: We analyze the daily data from the Bombay Stock Exchange using the methodology of Edmonds et al. (2007). This methodology has the advantages of capturing the Bombay Stock Exchange stock returns timevarying volatility through a GARCH model.

Major Fundings: Our findings show that cricket wins and losses do not impact the Bombay Stock Exchange. On the exchange, stock prices reflect relevant information. Our results are thus consistent with the Efficient Market Hypothesis.

Implication(s): Our results imply that on the Bombay Stock Exchange, cricket wins and losses cannot be reliably used by investors and portfolio managers to achieve returns in excess of the average market returns on a risk-adjusted basis.

Keywords: Sentiment, Sports Sentiment, Investor mood, ARCH, GARCH, Bombay Stock Exchange

\section{Introduction}

Recent work in cognitive psychology suggests that mood has a significant effect on the way information is processed (Gear et al., 2017). Good mood induces optimistic behaviors while bad mood encourages pessimistic behaviors. Since optimists expect that more good (desirable) things will happen in the future than bad (undesirable) things, optimists tend to pay less attention than pessimists (Scheier and Carver, 1985). Pessimists are prone to worry and devote more time to processing information (Schwarz, 2002). The relationship between peoples' state of mind and the way they process information is called the mood-as-information theory (Bless et al., 1990).

* Corresponding author.

E-Mail address: fbeer@csusb.edu 
The mood-as-information theory explains why studies have established a relationship between investors' mood and asset prices. Shu (2010) reports a positive relationship between equity prices and investors' mood. Cohen et al., (2013) find that investors' mood on a specific day impacts NASDAQ opening prices. Au et al., (2003) establish that traders in a good mood lose money because they exhibit overconfidence and take unwarranted risks. Nofsinger (2005) shows that the market reacts faster following pessimistic news than after optimistic news.

Researchers have established the relationship between stock indices and non-economic events such as the weather (Saporoschenko, 2011), sleep patterns (Kamstra et al., 2000), seasonal affective disorder (Dolvin et al., 2009), daylight savings (Pinegar, 2002), and the position of the moon (Yuan et al., 2006).

Researchers have also established the relationship between stock indices and sporting events. Ashton et al., (2003) describe a significant relationship between the results of the English football team and the returns of the FTSE100 index on the London Stock Exchange. They report that wins are followed by favorable stock returns and losses by unfavorable returns. Edmans et al., (2007) report negative returns when the national soccer team of a country loses a game. Consistent with the theory of loss aversion, Ashton et al. (2003) explain that when the national soccer team wins, the national market does not increase. They also suggest that when the team loses, the national market decreases. As always, the reality is complex and controversial results are also reported. Demirhan's (2013) analysis of the Turkish soccer team matches from 1988-2011 shows that stock index is unaffected by wins but affected by losses of national teams. Klein et al. (2009) do not find a statistically significant relationship between the nations' stock returns and the European World Championship soccer match results.

Van Rees (2010) report the limited effect of Dutch soccer match results on the Dutch stock exchange, while Kang and Park's (2015) analysis of the Korean market indicates that the Korean soccer team only affect stock returns during the World Cup and the Asian Cup. Aygoren et al., (2008) find that matches played by Turkish Soccer clubs produce abnormal returns if those matches are played in Europe. Berument et al., (2013) report that Turkish economic agents increase their risk tolerance after soccer team wins. Botha and De Beer (2013) note that there is no correlation between national sporting events and abnormal asset returns in South Africa.

These studies show that when soccer is used, results vary according to the country analyzed. Additionally, they also show that very few studies analyze other sports. Among the few exceptions, the notable research of Edmans et al., (2007). These studies also explain the need to capture investors' mood (Beer et al., 2013).

To sum up, the empirical link between soccer matches and asset prices deserves further research since results are inconclusive and vary across different countries. Additionally, since very few studies have investigated the relationship between other sports and asset prices, studies focusing on other sports are needed as well.

In this study, we investigate the impact of cricket wins and losses on the Bombay Stock Exchange (BSE). We hypothesize that cricket wins or losses will drive investors' mood substantially and unambiguously so that the game outcomes will be powerful enough to impact asset prices. According to Guha (1998), during some cricket games "...normal life comes to a standstill, with hundreds of millions of Indians glued to their radios and television sets" (Guha, 1998 , p. 158). This observation provides strong a priori motivation for using cricket game outcomes to capture mood changes among investors in India. It is difficult to imagine other sporting events that will produce such a substantial and correlated mood swing in a large proportion of India's population. We also suggest that the popularity of cricket justifies the hypothesis that cricket game outcomes will impact a large enough portion of the population, i.e., enough investors to impact stock prices. Finally, we also suggest that the impact of cricket wins or losses will be highly correlated across the majority of individuals. 
In this paper, we examine these hypotheses using the BSE daily returns during a seven-year period beginning June $2^{\text {nd }}, 2008$ and ending on June $30^{\text {th }}, 2015$. Contrary to the Efficient Market Hypothesis (EMH)'s premise that asset prices properly reflect all information (Fama, 1998), our study assumes that in specific instances financial markets can be inefficient (Shiller, 2003; Beer et al., 2011). This paper is thus part of the literature that investigates the effect of investors' mood on asset prices (Cao \& Wei, 2005).

We believe that this research has important contributions. First, it focuses on a rarely studied mood variable (cricket game results) to evaluate the relationship between investors' sentiment and asset prices. Second, it uses data from an infrequently studied exchange, the BSE. Third, previous studies on the relationship between sports and sentiment point to contradictory results. Fourth, this study is important for practitioners since the relationship between sports events and market performance has the potential to impact their ability to generate positive returns.

This paper includes four parts; the first part establishes that cricket wins and losses can be used as a mood variable and introduces the BSE. The second part presents the hypotheses, the data and the methodology. The third part discusses the results. The final part evaluates research limitations, makes suggestions for future research directions, and concludes this research.

\section{Cricket and the Bombay Stock Exchange}

\section{Cricket}

As discussed in the previous section, research in psychology has established that individuals' mood affects their decisions (Dickhaut et al., 2003, Johnson \& Tversky, 1983). For soccer games, studies show that when their team wins, people feel joyful and happy. Alternatively, when their team loses they experience sadness and melancholy (Cialdini et al., 1976). Since the outcomes of soccer games impact mood, soccer is considered to be a mood variable.

To impact mood, cricket must also be considered a mood variable. A mood variable must exhibit three characteristics to impact asset prices (Edmands et al., 2007). First, the variable must affect a large enough segment of the population. Second, the influence of the event must be unambiguous in a sense that winning evokes a positive emotion and losing evokes a negative emotion. Third, the impact of the event must be highly correlated among a majority of individuals. Cricket wins and losses satisfy these three key characteristics.

First, cricket outcomes must influence the mood of a large segment of the population to impact investors and induce a market reaction. Guha (1998) report that during games, hundreds of millions of Indians are glued to their radios. The popularity of the game has grown drastically with the explosion of television ownership. In 1989, around 30 million Indian households had a television. Nowadays, when India's national team plays a game, an estimated 400 million people watch on television. Cricket is no longer an elite game; it is now a populist event. What was once commonly known as an English summer game has evolved toward a celebrity-infused, exceptionally politicized, billion-dollar industry. To sum up, since cricket outcomes have the potential to change the mood of a large enough portion of the population, cricket has the potential to impact the market.

Second, cricket outcomes drive mood substantially and unambiguously so that the game results are powerful enough to impact asset prices. Research has shown individuals strive to attach themselves to social groups that reflect positively on them. India's cricket fan-base exhibits similar characteristics. Since the popularity of the game has increased, being a known fan of the national team is viewed positively. India has won all of the International Cricket Council (ICC) Tournaments, including the ODI's World Cup twice (1983 \& 2011). India's victory at the ICC World Twenty20 in 2007 and the country performance during the ICC games of 2013 has also 
contributed to increasing the popularity of the sport. For Indians, winning a cricket game evokes positive emotions and losing evokes negative emotions.

Third, the impact of the mood variable must be correlated across a large number of individuals within the country. With the introduction of the Indian Premier League (IPL), people from all over the world have come to enjoy India's cricket game. India is known to have produced some of the most notable cricket athletes, including Kapil Dev, Sunil Gavaskar, Rahul Dravid and Sachin Tendulkar. Indians' affection for cricket is unfathomable. In February 2014, India granted the Bharat Ratna, its highest civilian honor, to Sachin Tendulkar. A nation of 1.3 billion individuals and just a single broadly prominent sporting event led cricket to become a nationally celebrated event.

\section{Bombay Stock Exchange}

Bombay Stock Exchange (BSE) Limited is the oldest stock exchange in Asia. The exchange history can be traced back to the 1850s when a group of five stockbrokers started to conduct meetings under a banyan tree in front of the town hall in Mumbai. As the number of stockbrokers increased, the group eventually moved to the Dalal Street, and the BSE was born. The exchange was established as "The Native Share \& Stock Brokers Association" in 1875. It was the first stock exchange in the country to obtain permanent recognition from the Government of India under the Securities Contracts Act of 1956.

The BSE's long lifespan has resulted in the exchange having more than 7,152 listings and a market capitalization of more than $\$ 1.5$ trillion. The largest company traded includes: Bharat Heavy Electrical ( $₹{ }^{1} 33189.46 \mathrm{Cr}^{2}$ ), Bharat Petroleum (₹ 84868.4 Cr), HDFC Bank (₹ 325481.72 Cr), ICICI Bank (₹ 151788.95 Cr), INFOSYS Technologies Limited (₹ 238342.46 Cr), State Bank of India (₹ $195427.91 \mathrm{Cr}$ ), Tata Motors (₹ $156274.55 \mathrm{Cr}$ ), and Wipro Technologies (₹ 117577.45 Cr). A brief comparison between the BSE, NYSE, and NASDAQ is presented in Table 1.

Table 1. BSE, NASDAQ and NYSE

\begin{tabular}{llll}
\hline & BSE & NASDAQ & NYSE \\
\hline \# listed & 7,152 & 3,211 & 3,155 \\
Market cap & $\$ 1.5$ trillion & $\$ 7.8$ trillion & $\$ 19.6$ trillion \\
Location & Mumbai, India & NY, United States & NY, United States \\
$\#$ members & 1428 & 189 & 162 \\
Established in & 1875 & 1971 & 1792 \\
Initial Fees & $\$ 425$ & $\$ 50,000-\$ 125,000+$ & $\$ 100,000-\$ 150,000$ \\
Revenue & $\$ 104$ million $(2016)$ & $\$ 2.3$ billion $(2016)$ & $\$ 3.3$ billion $(2015)$
\end{tabular}

BSE stands for the Bombay Stock Exchange, \# listed is the number of companies listed and \# members the number of members.

As shown, the BSE has more than twice the number of companies listed than the NYSE and NASDAQ. Nonetheless, the larger number of companies listed, the BSE market capitalization is barely $19 \%$ of the market capitalization of NASDAQ and $7.65 \%$ of the market capitalization of

\footnotetext{
1 ₹ denotes Indian currency Rupees

${ }^{2} \mathrm{Cr} .=$ Indian numbering system, scientific notation: $10^{7}$
} 
the NYSE. The BSE revenues in 2016 were 104 million U.S. dollars, 20 times lower than NASDAQ and NYSE.

The SENSEX is the BSE key index. Figure 1 compares the Dow Jones ${ }^{3}$ (DJIA) and the SENSEX daily closing value for the period starting in 2008 and ending in 2015 , i.e. the period studied.

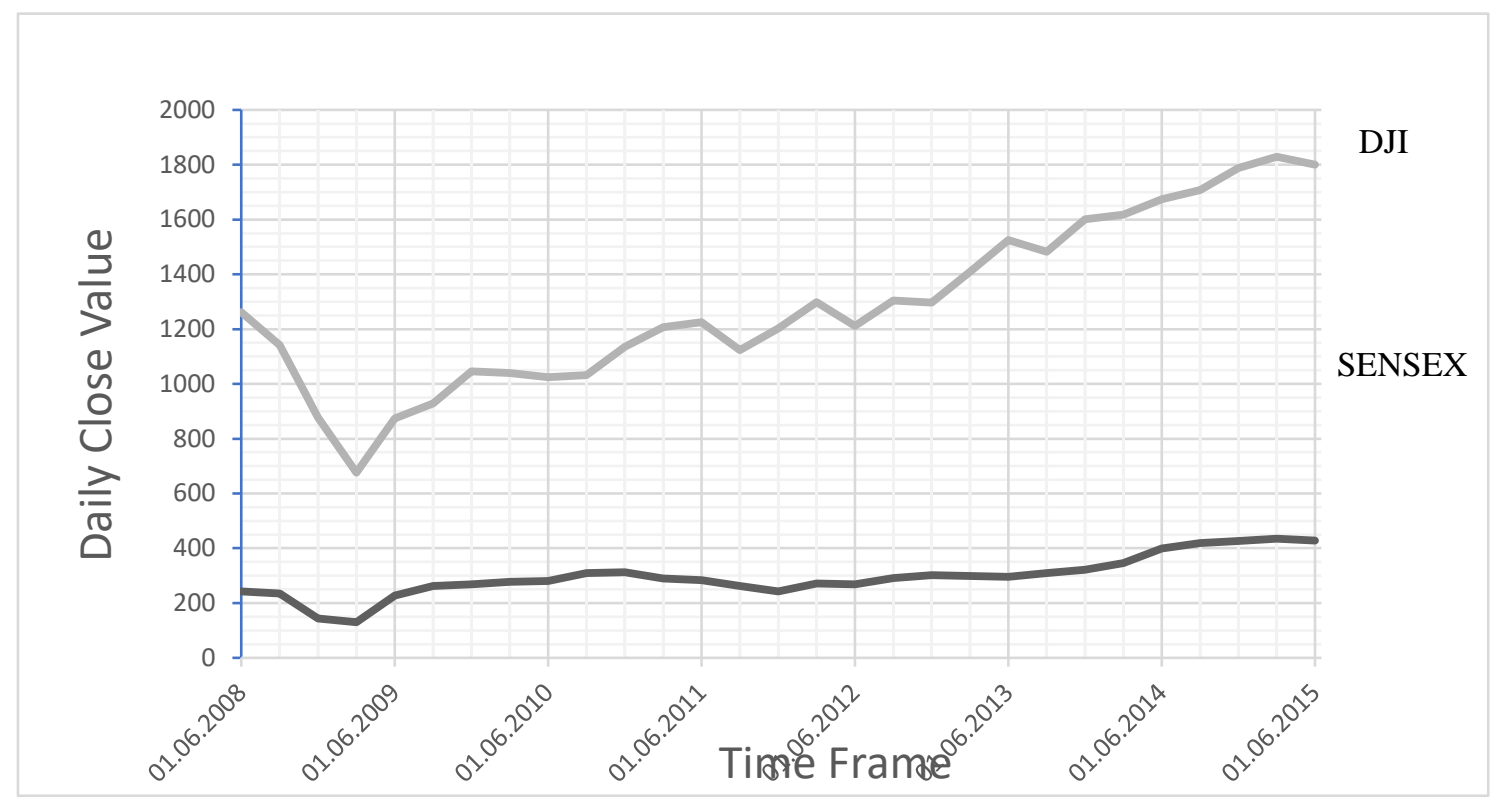

Due to the low currency exchange rate from Rupees to USD, the DJIA has been adjusted. ${ }^{3}$

Figure 1. SENSEX and DJIA

As shown in the graph above, the DJIA and the SENSEX exhibit a similar trend. Note however, that the DJIA decreases more than the SENSEX during the 2008 crisis. The DJIA increases faster than the SENSEX after the 2008 crisis.

\section{Hypotheses, Data and Methodology}

\section{Hypotheses}

Our null hypothesis states that the BSE is not influenced by cricket outcomes. This hypothesis implies that the BSE is efficient and that Indian investors are rational. This hypothesis runs contrary to the findings of the psychology literature that suggest fans' moods are affected by sports outcomes. The alternative hypothesis states that the BSE is impacted by cricket outcomes. The null and the alternative hypotheses are presented below:

\section{$H_{0}$ : Asset prices on the BSE are not impacted by the outcomes of cricket games. \\ $H_{1}$ : Asset prices on the BSE are impacted by the outcomes of cricket games.}

As written, the alternative hypothesis does not account for the fact that abnormal returns are more likely to be associated with losses than with wins. As discussed in the literature section of this manuscript, several studies have suggested that losses are psychologically more powerful than

\footnotetext{
${ }^{3}$ Accurate representation of the DJIA is 10 times the value presented in the figure.
} 
wins. Loss aversion was first demonstrated by Kahneman and Tversky (1984). To account for these findings, a third hypothesis is tested.

$H_{3}:$ Asset prices on the BSE are impacted more by losses than by wins.

Data

Our study uses daily SENSEX data over the period from June $2^{\text {nd }}, 2008$ through June $30^{\text {th }}, 2015$. Data were obtained from CMIE Prowess ${ }^{4}$. The daily index returns are calculated using the standard return formula:

With:

$$
R_{B S E, t}=\ln \left(\frac{P_{t}}{P_{t-1}}\right) * 100
$$

$R_{B S E, t}$
$P_{t}$
$P_{t-1}$
$\ln$

The daily returns at the end of day $t$.

The SENSEX index at the end of day $t$.

The index at the end of the previous day.

The natural log.

During the seven years studied, the Indian cricket team ${ }^{5}$ played 112 matches, winning 77 matches and losing 35 matches. Data from the matches were gathered from ESPN Sports Media $\mathrm{Ltd}^{6}$. In this study, we focused on weekdays only, i.e., days during which the market is open. We also only analyze wins and losses, ignoring ties.

\section{Methodology}

The three hypotheses discussed in the previous section are evaluated using a methodology similar to Edmans et al., (2007). The methodology is described below.

We start with the estimation of equation 2. Equation 2 presented below expresses $R_{B S E, t}$ as a function of variables controling for the book-to-market (HML), size (SMB), and days of the week (Day). The equation also accounts for the first order serial correlation by using the lagged index returns $\left(R_{B S E, t-1}\right)$.

$$
R_{B S E, t}=\beta_{0}+\beta_{1} R_{B S E, t-1}+\beta_{2} R_{S M B, t}+\beta_{3} R_{H M L, t}+\beta_{4} D a y_{M}+\beta_{5} D a y_{T u}+\beta_{6} D a y_{T h}+\beta_{7} D_{B S E, t}+
$$

With:

$\mathrm{R}_{\mathrm{BSE}, \mathrm{t}} \quad$ The BSE stock return in period $\mathrm{t}$.

$\mathrm{R}_{\mathrm{BSE}, \mathrm{t}-1} \quad$ The BSE stock return in $\mathrm{t}-1$.

\footnotetext{
${ }^{4}$ CMIE Prowess is the Largest Database of Indian Companies.

${ }^{5}$ The data studied consists of one Cricket team called the "India national cricket team" which represents India in international matches.

${ }^{6}$ The results of the matches are obtained from the website http://www.espncricinfo.com/
} 
$\mathrm{Day}_{, \mathrm{M}, \mathrm{TU}, \mathrm{TH}, \mathrm{F}}$

$\mathrm{R}_{\mathrm{SMB}, \mathrm{t}}$

$\mathrm{R}_{\mathrm{HML}, \mathrm{t}}$

$\varepsilon_{\mathrm{BSE}, \mathrm{t}}$
A series of dummy variables that correspond to the day of the week. ${ }^{7}$

The return on a zero-investment portfolio that is long on small asset stocks and short on large value stocks.

The return on a zero-investment portfolio that is long on high book-to-market value stocks and short on low book-to-market value stocks.

The residuals.

Using the estimated residuals from equation $2\left(\hat{\varepsilon}_{B S E, t}\right)$, we then evaluate the impact of the cricket outcomes using two dummy variables. The first dummy variable $W_{i t}$ equals one when India wins the game and zero otherwise. The second dummy variable $L_{i t}$ equals one when India losses the game and zero otherwise. The model is presented in equation 3.

$$
\hat{\varepsilon}_{B S E, t}=\alpha_{0}+\alpha_{w i n} W_{i t}+\alpha_{\text {Lose }} L_{i t}+u_{i t}
$$

With:
$W_{i t}$
A dummy variable that equals one when India wins the game and zero otherwise.
$L_{i t}$ A dummy variable that equals one when India losses the game and zero otherwise.
$u_{i t}$
The residuals.

Equation 3 is estimated using a $\operatorname{GARCH}(1,1)$ model to account for the fact that most stock indices exhibit time-varying volatility (Bollerslev et al., 1994). As depicted in Figure 2, this characteristic of the stock indices returns appears to be present on the BSE.

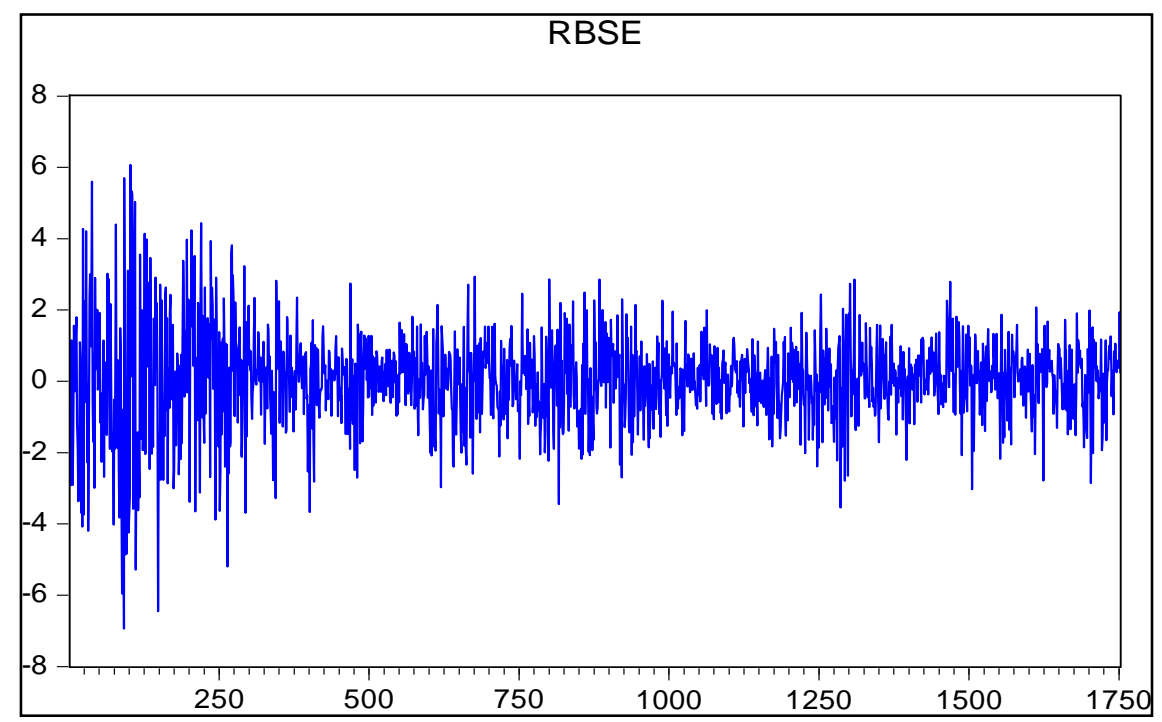

Figure 2. BSE Daily returns (RBSE)

Figure 2 shows that the BSE exhibits volatility clustering. The BSE is thus similar to other exchanges in which successive disturbances, although uncorrelated, are nonetheless serially

${ }^{7}$ Notice that Wednesday is omitted from the regression to avoid the dummy variable trap. 
dependent. The correlogram of squared residuals presented in Table 2 supports using a GARCH $(1,1)$ model.

Table 2. Q-Stats

\begin{tabular}{lll}
\hline Lag & Auto Correlation & Partial Correlation \\
\hline 1 & 0.910 & 0.910 \\
2 & 0.906 & 0.455 \\
3 & 0.907 & 0.319 \\
4 & 0.901 & 0.191 \\
5 & 0.878 & -0.023 \\
6 & 0.880 & 0.069 \\
7 & 0.860 & -0.063 \\
8 & 0.864 & 0.089 \\
9 & 0.844 & -0.046 \\
10 & 0.843 & 0.041 \\
\hline
\end{tabular}

The adequacy of the GARCH $(1,1)$ model is further evaluated by the Ljung-Box test. Since adequate models are characterized by white noise residuals, i.e., identically and independently distributed residuals, $Q(m)$ should be 0 for any lag $m$. As shown in Table 3 the $Q(m)$ are not significantly different from zero for up to 10 lags.

Table 3. Ljung-box

\begin{tabular}{lll}
\hline Lag & Q-Stats & Probability \\
\hline 1 & 1452.3 & 0.000 \\
2 & 2893.9 & 0.000 \\
3 & 4338.4 & 0.000 \\
4 & 5764.3 & 0.000 \\
5 & 7120.6 & 0.000 \\
6 & 8482.4 & 0.000 \\
7 & 9784.9 & 0.000 \\
8 & 11099 & 0.000 \\
9 & 12354 & 0.000 \\
10 & 13607 & 0.000 \\
\hline
\end{tabular}

Accordingly, we model the volatility of the error terms from equation 2 as a GARCH $(1,1)$ using the following:

$$
\sigma_{B S E, t}^{2}=\theta_{0}+\theta_{1} \varepsilon_{B S E, t-1}^{2}+\theta_{2} \sigma_{B S E, t-1}^{2}+v_{t}
$$


With:

$\sigma_{B S E, t}^{2}$

The BSE index return volatility in $t$.

$\boldsymbol{\sigma}_{B S E, t-1}^{2} \quad$ The BSE index return volatility in t-1.

$\varepsilon_{B S E, t-1}^{2} \quad$ The residuals squared estimated from equation (2).

$v_{t}$

The residuals.

Finally, we use the time series of estimated volatility $\left(\hat{\sigma}_{B S E, t}^{2}\right)$ to form a new time series of normalized returns as depicted in equation 5 below. These normalized returns are then used in equation 2 .

$$
R_{B S E, t}^{\text {Normalized }}=\delta_{1 B S E}+\delta_{2 B S E}\left(\frac{1}{\hat{\sigma}_{B S E, t}^{2}}\right) R_{B S E, t}
$$

With:

$\begin{array}{ll}R_{B S E, t}^{\text {Normalized }} & \text { The normalized BSE stock return in period t. } \\ R_{B S E, t} & \text { The BSE stock return in period t. } \\ \delta_{1 B S E} \& \delta_{2 B S E} & \begin{array}{l}\text { Parameters selected so that the mean of } R_{B S E, t}^{\text {Normalized }} \text { is equal to zero and the } \\ \text { standard deviation is equal to one. }\end{array} \\ \hat{\sigma}_{B S E, t}^{2} & \text { The BSE estimated volatility in period t. }\end{array}$

\section{Descriptive Statistics and Findings}

\section{The Descriptive Statistics}

The descriptive statistics are summarized in Table 4. The table shows that the maximum daily returns are above $5 \%$ for all three series. It also shows that the minimum daily returns are greater than $-6.9 \%$ and that the standard deviations do not exceed $1.3 \%$. With kurtosis coefficients of 6.53 for $R_{S M B}, 6.76$ for $R_{H M L}$, and 5.91 for $R_{B S E}$, the return distributions are inconsistent with the assumption of normality. The skewness coefficients which are respectively -0.219 for $R_{B S E}$ and 0.228 for $R_{S M B}$ suggest longer left tail distributions than the normal distribution. The positive skewness coefficient of 0.158 for $R_{H M L}$ leads to the opposite conclusion. The Jarque-Bera coefficients of 929 for $R_{S M B}, 1043$ for $R_{H M L}$, and 634 for $R_{B S E}$ all with a $p<0.01$ support these observations. The return distributions for these variables are inconsistent with the assumption of normality. The average return on Friday $(0.028 \%)$ is lower than the average daily return on Monday $(0.077 \%)$. Finally, when India participates in a cricket tournament, the average daily return reaches $13 \%$. 
Table 4. Descriptive Statistics

\begin{tabular}{|c|c|c|c|c|c|c|c|c|c|}
\hline & Mean & Max & Min & Std. Dev. & Skewness & Kurtosis & Jarque-Bera & Prob. & Obs. \\
\hline $\mathrm{R}_{\mathrm{BSE}}$ & 0.0383 & 6.069 & -6.936 & 1.3 & -0.219 & 5.916 & 634.84 & 0 & 1380 \\
\hline $\mathrm{R}_{\mathrm{SMB}}$ & 0.0127 & 6.039 & -4.269 & 0.847 & -0.228 & 6.539 & 929.89 & 0 & 1380 \\
\hline $\mathrm{R}_{\mathrm{HML}}$ & -0.002 & 5.449 & -5.218 & 0.937 & 0.158 & 6.766 & 1043.07 & 0 & 1380 \\
\hline Mon & 0.07700 & 5.69931 & -5.9546 & 1.42348 & -0.19192 & 5.590360 & 100.5737 & 0 & 352 \\
\hline Friday & 0.02808 & 5.33146 & -6.9362 & 1.33535 & -0.32434 & 5.943054 & 129.4238 & 0 & 342 \\
\hline Game & 0.13648 & 1.08521 & 0.00055 & 0.16868 & 2.953962 & 13.53154 & 680.4789 & 0 & 112 \\
\hline
\end{tabular}

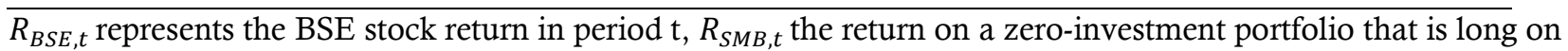
small asset value stocks and short on large asset value stocks, $R_{H M L, t}$ the return on a zero-investment portfolio that is long on high book-to-asset value stocks and short on low book-to-asset value stocks. Std.Dev stands for the standard deviation, Prob for the probability and Obs for the number of observations.

Before we proceed further, we perform unit roots tests to evaluate whether the BSE is stationary. The stationarity of a series can strongly influence its behavior and properties. When a series is non-stationary, the persistence of stocks could be infinite. Both ADF (-37.50) and PP (37.49 ) tests reject the null hypothesis of non-stationary at the $5 \%$ level.

Table 5. ADF, PP and GARCH model

\begin{tabular}{|c|c|c|c|c|c|}
\hline \multicolumn{6}{|l|}{ Panel A. } \\
\hline & \multicolumn{2}{|c|}{$\mathrm{R}_{\mathrm{BSE}}$} & $\mathrm{R}_{\mathrm{SMB}}$ & \multicolumn{2}{|c|}{$\mathrm{R}_{\mathrm{HML}}$} \\
\hline $\mathrm{ADF}$ & \multicolumn{2}{|c|}{$-37.50 * * *$} & $-40.603^{* * *}$ & \multicolumn{2}{|c|}{$-36.498^{* * *}$} \\
\hline $\mathrm{PP}$ & \multicolumn{2}{|c|}{-37.492} & $-40.606^{* * *}$ & \multicolumn{2}{|c|}{$-36.498^{* * *}$} \\
\hline \multicolumn{6}{|l|}{ Panel B. } \\
\hline & Coefficient & Std. Error & Probability & $\mathrm{R}^{2}$ & Adjusted $\mathrm{R}^{2}$ \\
\hline $\mathrm{C}$ & 0.008636 & 0.00284 & 0.0024 & 0.226231 & 0.222677 \\
\hline $\mathrm{ARCH}(1)$ & 0.075816 & 0.01074 & 0 & & \\
\hline GARCH(1) & 0.916139 & 0.01072 & 0 & & \\
\hline Akaike & Schwartz & \multicolumn{2}{|c|}{ Hannan-Quinn } & Watson & Log-likelihood \\
\hline 2.7 & 2.737 & 2.714 & \multicolumn{2}{|c|}{1.973} & 2352.089 \\
\hline
\end{tabular}




\section{The Garch Model}

The findings from the GARCH model are presented in Table 6 . As shown in the table the $R^{2}$ and adjusted $R^{2}$ being above $22 \%$ the model adequately predicts the series volatility. The Akaike Information Criterion (AIC), Schwartz Information Criterion (SIC), Hannan-Quinn (HQ), and Log Likelihood were also calculated ${ }^{8}$.

The coefficients of the ARCH $(1)$ and $\operatorname{GARCH}(1,1)$ are all positive and significant. These positive coefficients include the estimated coefficient for the constant term in the conditional variance $\left(\theta_{0}\right)$, the estimated coefficient of the lag value of the square residual term $\left(\theta_{1}\right)$, and the estimated coefficient of the lag value of the conditional variance $\left(\theta_{2}\right)$.

After having appraised the suitability of the GARCH $(1,1)$ model, we proceed with the calibration of equation 2. Results are presented in Table 6 and are divided into two panels. Panel A depicts the results using the initial returns and Panel B the results when normalized returns are used.

The regression coefficients in Panel A (the regression using the initial returns) are significant for the independent variables $\mathrm{R}_{\mathrm{SMB}}, \mathrm{R}_{\mathrm{HML}}, R_{B S E, t-1}$ and the variables representing the day of the week Monday and Friday. The coefficient for the variable $\mathrm{R}_{S M B}$ is negative and significant. While the coefficients for $\mathrm{R}_{\mathrm{HML}}$ and $R_{B S E, t-1}$ are positive and significant. The regression coefficients in Panel $\mathrm{B}$ are similar. When the normalized returns are used, the coefficients for $\mathrm{R}_{\mathrm{SMB}}, \mathrm{R}_{\mathrm{HML}}$, and the normalized lag returns $\left(R_{B S E, t-1}\right)$ are significant. The coefficient for $\mathrm{R}_{\mathrm{SMB}}$ remains negative and significant, while the coefficients for $\mathrm{R}_{\mathrm{HML}}$ and $R_{B S E, t-1}$ are significantly positive.

The significantly negative coefficient for $R_{S M B}$ indicates that on the BSE, large-cap stocks outperform small-cap stocks. The positive and significant coefficient for $\mathrm{R}_{\mathrm{HML}}$ implies that high book-to-market stocks (value stocks and growth stocks) outperform low book-to-market stocks.

8 The Akaike Information Criterion (AIC), Schwartz Information Criterion (SIC), Hannan-Quinn (HQ), and Log Likelihood are normally used to compare the goodness of fit of one model with another. 
Table 6. GARCH Results

\begin{tabular}{|c|c|c|c|c|c|}
\hline \multicolumn{6}{|l|}{ Panel A. } \\
\hline & Coefficient & & Std. Error & $\mathrm{R}^{2}$ & Adjusted $\mathrm{R}^{2}$ \\
\hline$\beta_{0 t}$ & 0.053827 & * & 0.213449 & 0.287775 & 0.283557 \\
\hline $\mathrm{R}_{\mathrm{SMB}}$ & -0.482573 & $* * *$ & 0.023682 & & \\
\hline $\mathrm{R}_{\mathrm{HML}}$ & 0.311291 & $* * *$ & 0.017612 & & \\
\hline $\mathrm{R}_{\mathrm{BSE}, \mathrm{t}-1}$ & 0.135821 & $* * *$ & 0.21868 & & \\
\hline Monday & -0.031922 & * & 0.218209 & & \\
\hline Tuesday & -0.003839 & * & 0.217972 & & \\
\hline Thursday & 0.011683 & & 0.218627 & & \\
\hline Friday & -0.035065 & & 0.21711 & & \\
\hline Akaike & Schwartz & & Hannan-Quinn & Durbin Watson & Log-likelihood \\
\hline 2.723 & 2.757 & & 2.736 & 1.719 & -2374.897 \\
\hline
\end{tabular}

Panel B.

\begin{tabular}{llllll}
\hline & Coefficient & & Std. Error & $\mathrm{R}^{2}$ & Adjusted $\mathrm{R}^{2}$ \\
\hline$\beta_{0 t}$ & 0.016179 & $*$ & 0.139724 & 0.208781 & 0.308013 \\
$\mathrm{R}_{\mathrm{SMB}}$ & -0.009026 & $* * *$ & 0.010605 & & \\
$\mathrm{R}_{\mathrm{HML}}$ & 0.010671 & $* * *$ & 0.012532 & & \\
$\mathrm{R}_{\mathrm{BSE}, \mathrm{t}-1}$ & 0.910443 & $* * *$ & 0.011296 & & \\
Monday & -0.011852 & $*$ & 0.141670 & & \\
Tuesday & -0.034791 & $*$ & 0.141696 & & \\
Thursday & 0.012322 & & 0.141714 & & \\
Friday & -0.025873 & & 0.141814 & & Dog-likelihood \\
\hline Akaike & Schwartz & & Hannan-Quinn & Watson & Lurbin \\
\hline 1.207 & 1.235 & & 1.218 & 2.835 & -1047.769
\end{tabular}

$\overline{\beta_{0 t} \text { represents the constant term, } \mathrm{R}_{\mathrm{SMB}} \text { the return on a zero-investment portfolio that is long on small asset value }}$ stocks and short on large asset value stocks, $\mathrm{R}_{\mathrm{HML}}$, the return on a zero-investment portfolio that is long on high book-to-asset value stocks and short on low book-to-asset value stocks and $\mathrm{R}_{\mathrm{BSE}, \mathrm{t}-1}$ is the BSE stock return in $\mathrm{t}-1$. $*, * *, * * *$ denotes statistically significant at $10 \%, 5 \%$ and $1 \%$ respectively.

The $\alpha_{\text {win }}$ and $\alpha_{\text {lose }}$ estimates from equation 3 are presented in Table 7 which is organized similarly to the previous table, i.e., Panel A shows the results for the initial returns and Panel B for the normalized returns. In both panels the $\alpha_{\text {win }}$ and $\alpha_{\text {lose }}$ estimates are not statistically different from zero. These estimates are negative when the initial returns are used. When the GARCH $(1,1)$ volatility adjustment and the normalized returns are used, $\alpha_{\text {win }}$ and $\alpha_{\text {lose }}$ remain insignificant, however the sign of $\alpha_{\text {lose }}$ is now positive. 
Table 7. Wins and Losses

\begin{tabular}{|c|c|c|c|}
\hline \multicolumn{4}{|l|}{ Panel A. } \\
\hline & Coefficient & Std. Error & t-Statistic \\
\hline$\alpha_{\text {win }}$ & -0258047 & 0.157947 & -1.633757 \\
\hline$\alpha_{\text {lose }}$ & -0130223 & 0.193445 & -0.673177 \\
\hline \multicolumn{4}{|l|}{ Panel B. } \\
\hline & Coefficient & Std. Error & t-Statistic \\
\hline$\alpha_{w i n}$ & -0.426187 & 0.128007 & -3.329397 \\
\hline$\alpha_{\text {lose }}$ & 0.0102831 & 0.170142 & 0.604384 \\
\hline
\end{tabular}

$\alpha_{\text {win }}$ represents the return value when India wins and $\alpha_{\text {lose }}$ represents the return when India losses.

\section{Conclusion}

This study explores the impact of cricket wins and losses on the Bombay Stock Exchange (BSE). It is directly related to psychological research that shows how individual mood affects individual choices (Dickhaut et al., 2003). It is motivated by several factors. First, most previous studies focus on soccer. Second, the BSE is an under-researched market. Third, previous studies on the relationship between sports and sentiment point to contradictory results. Fourth, since the relationship between sporting events and market performance has the potential to impact investors' ability to generate positive returns, this study is important for investors.

We hypothesize that cricket outcomes will drive investors' mood in a sizeable and unequivocal way so that the game outcomes will sway asset prices (Hirt et al., 1992). Additionally, since numerous studies have suggested that investors react more strongly to losses than to wins, we also hypothesize that asset prices on the BSE will be impacted more by losses than by wins. These hypotheses are tested using daily data and the BSE SENSEX index for the period June $2^{\text {nd }}, 2008$ to June $30^{\text {th }}, 2015$.

The BSE series exhibits negative skewness (-0.219), high kurtosis (5.9), and a significant Jarque-Bera coefficient (634.8). Our results are thus similar to those reported by Gupta and Basu (2007). The authors show that the BSE does not display the characteristics of a random walk. As such, the market is not efficient in the weak form. The PP test performed by the authors shows that the series is stationary.

Our analysis confirms that the constant-volatility assumption is problematic because the BSE stock returns exhibit time-varying volatility (Bollerslev et al., 1994). Consequently, the effect of our standard errors could be negatively biased if any of our sampled games took place during highly volatile periods. This characteristic of the BSE is handled through a GARCH model.

Our findings show that cricket wins and losses do not impact the BSE. Further, since results for losses are inconclusive, the hypothesis of loss aversion cannot be established when the BSE is analyzed. On the BSE, cricket wins and losses do not impact prices. Our results are thus similar to those reported by Ashton et al., (2003), Gerlach, (2011), and Kaplanski and Levy, (2010).

Our results imply that on the BSE, cricket wins and losses cannot be reliably used by investors to achieve returns in excess of the average market returns on a risk-adjusted basis. When cricket wins and losses are analyzed, the BSE is efficient. Our results can also be explained by the structure of ownership of the market. While cricket is considered an important sporting event for the average Indian citizen, only a tiny percentage of Indian household savings is invested in the domestic stock market. The critical issue that holds many back from investing in the BSE is that 
it is not highly liquid. As the percentage of the household investing in the market increases, the hypothesis tested in this paper should be re-evaluated. At this stage, we are concluding that cricket wins and losses do not have a pervasive impact on investors' mood. On the BSE, asset prices do not fluctuate in response to cricket-related events.

As suggested by Lee and Chiu (2016), future studies using the BSE should consider not only the market closing prices but also the market opening prices to estimate excess stock returns. In an efficient market, if a team wins or loses a game that is played during the evening, a market reaction could be detected when the market opens the following day. Future studies should also consider using individual companies. It is possible that cricket outcomes will have a significant impact on the excess stock returns of some companies but not others.

\section{References}

Ashton, J. K., Gerrard, B., \& Hudson, R. (2003). Economic impact of national sporting success: Evidence from the London stock exchange. Applied Economics Letters, 10(12), 783-785. doi:10.1080/1350485032000126712

Au, K., Chan, F., Wang, D., \& Vertinsky, I. (2003). Mood in foreign exchange trading: Cognitive processes and performance. Organizational Behavior and Human Decision Processes, 91(2), 322-338.

Aygoren, H., Uyar, C., \& Saritas, H. (2008). Are Investors Affected by Match Results? Application to Istanbul Stock Exchange. H.U. Iktisadi ve Idari Bilimler Fakultesi Dergisi 26(1), 121-137.

Beer, F., Nouyrigat, G., \& Zouaoui, M. (2011). How does investor sentiment affect stock market crises? Evidence from panel data. Financial Review, 46(4), 723-747.

Beer, F., \& Zouaoui, M. (2012). Measuring Stock Market Investor Sentiment. Journal of Applied Business Research (JABR), 29(1), 51-68. doi:10.19030/jabr.v29i1.7555

Berument, M. H., Ceylan, N. B., \& Onar, B. (2013). Football and the Risk-Return Relationship for a Stock Market: Borsa Istanbul. Emerging Markets Finance and Trade, 49(2), 19-30. doi:10.2753/ree1540-496x490202

Bless, H., Bohner, G., Schwarz, N., \& Strack, F. (1990). Mood and persuasion: A cognitive response analysis. Personality and social psychology bulletin, 16(2), 331-345.

Bollerslev, T., Engle, \& R., Nelson, D. (1994), "ARCH models", in H\&book of Econometrics (Vol. IV), ed. R.Engle and D. McFadden , Amsterdam: North Holland, pp. 2959 - 3038.

Botha, F., \& De Beer, C. (2013). Does national sporting performance affect stock market returns in South Africa?. Journal of Economic \& Financial Sciences, 6(1), 67-82.

Cao, M., \& Wei, J. (2005). Stock market returns: A note on temperature anomaly. Journal of Banking \& Finance, 29(6), 1559-1573. doi:10.1016/j.jbankfin.2004.06.028

Cialdini, R. B., Thornê, A., Borden, R. J., Walker, M., Freeman, S., \& Sloan, L. R. (1976). Basking in reflected glory: Three (football) field studies. Journal of Personality and Social Psychology, 34(3), 366-375. doi:10.1037//0022-3514.34.3.366

Cohen, A. S., Kim, Y., \& Najolia, G. M. (2013). Psychiatric symptom versus neurocognitive correlates of diminished expressivity in schizophrenia and mood disorders. Schizophrenia research, 146(1-3), 249-253.

Demirhan, D. (2013). Stock Market Reaction To National Sporting Success: Case Of Istanbul Stock Exchange. Pamukkale Journal of Sport Sciences, 4(3), 107-121.

Dickhaut, J., McCabe, K., Nagode, J. C., Rustichini, A., Smith, K., \& Pardo, J. V. (2003). The impact of the certainty context on the process of choice. Proceedings of the National Academy of Sciences of the United States of America, 100(6), 3536-3541. http://doi.org/10.1073/pnas.0530279100

Dolvin, S. D., Pyles, M. K., \& Wu, Q. (2009). Analysts Get SAD Too: The Effect of Seasonal Affective Disorder on Stock Analysts Earnings Estimates. Journal of Behavioral Finance, 10(4), 214-225. doi:10.1080/15427560903372809

Edmans, A., García, D., \& Norli, Ø. (2007). Sports Sentiment and Stock Returns. The Journal of Finance, 62(4), 1967-1998. doi:10.1111/j.1540-6261.2007.01262.x

Fama, E. F. (1997). Market Efficiency, Long-Term Returns, and Behavioral Finance. SSRN Electronic Journal, 49(3), 283-306. doi:10.2139/ssrn.15108

Gear, T., Shi, H., Davies, B. J., \& Fets, N. A. (2017). The impact of mood on decision-making process. EuroMed Journal of Business, 12(3), 242-257.

Gerlach, J. R. (2011). International sports and investor sentiment: do national team matches really affect stock market returns? Applied financial economics, 21(12), 863-880. 
Guha, R. (1998). Cricket And Politics In Colonial India. Past \& Present, 161(1), 155-190. doi:10.1093/past/161.1.155

Gupta, R., \& Basu, P. K. (2011). Weak Form Efficiency In Indian Stock Markets. International Business \& Economics Research Journal (IBER), 6(3), 57-64. doi:10.19030/iber.v6i3.3353

Hirt, E. R., Zillmann, D., Erickson, G. A., \& Kennedy, C. (1992). Costs and benefits of allegiance: Changes in fans self-ascribed competencies after team victory versus defeat. Journal of Personality and Social Psychology, 63(5), 724-738. doi:10.1037//0022-3514.63.5.724

Johnson, E. J., \& Tversky, A. (1983). Affect, generalization, and the perception of risk. Journal of Personality and Social Psychology, 45(1), 20-31. http://dx.doi.org/10.1037/0022-3514.45.1.20

Kahneman, D., \& Tversky, A. (1984). Choices, values, and frames. American Psychologist, 39(4), 341350.http://dx.doi.org/10.1037/0003-066X.39.4.341

Kamstra, M. J., Kramer, L. A., \& Levi, M. D. (2002). Losing Sleep at the Market: The Daylight Saving Anomaly: Reply. American Economic Review, 92(4), 1257-1263. doi:10.1257/00028280260344795

Kang, I., \& Park, C. (2014). Soccer sentiment and investment opportunities in the Korean stock market. Asia-Pacific Journal of Accounting \& Economics, 22(2), 213-226. doi:10.1080/16081625.2014.960432

Kaplanski, G., \& Levy, H. (2010). Exploitable Predictable Irrationality: The FIFA World Cup Effect on the U.S. Stock Market. Journal of Financial and Quantitative Analysis, 45(02), 535-553. doi:10.1017/s0022109010000153

Klein, C., Zwergel, B., \& Heiden, S. (2009). On the existence of sports sentiment: The relation between football match results and stock index returns in Europe. Review of managerial science, 3(3), 191-208.

Lee, J. S., \& Chiu, C. W. (2016). Sport Sentiments and Stock Returns: Example of FIFA World Cups. Applied Economics and Finance, 4(2), 44-56.

Nofsinger, J. R. (2005). Social mood and financial economics. The Journal of Behavioral Finance, 6(3), 144-160.

Pinegar, J. Michael. "Losing Sleep at the Market: The Daylight Savings Anomaly: Comment." American Economic Review, September 2002, 92(4), pp. 1251-56.

Saporoschenko, A. (2011). The effect of Santa Ana wind conditions and cloudiness on Southern California stock returns. Applied Financial Economics, 21(10), 683-694. doi:10.1080/09603107.2010.535785

Schwarz, N. (2002). Feelings as information: moods influence judgment and processing strategies. In T. Gilovich, D. Griffin, \& D. Kahneman (Eds.), Heuristics and biases: The psychology of intuitive judgment (pp. 534547). New York: Cambridge University Press.

Scheier, M. F., \& Carver, C. S. (1985). Optimism, coping, and health: assessment and implications of generalized outcome expectancies. Health psychology, 4(3), 219.

Shiller, R. J. (2003). From Efficient Markets Theory to Behavioral Finance. Journal of Economic Perspectives, 17(1), 83-104. doi:10.1257/089533003321164967

Shu, H. C. (2010). Investor mood and financial markets. Journal of Economic Behavior \& Organization, 76(2), 267282.

Van Rees, N., \& Bersem, D. M. (2010). Sport Sentiment \& Stock Returns: The Dutch soccer team. University of Amsterdam.

Yuan, K., Zheng, L., \& Zhu, Q. (2006). Are investors moonstruck? Lunar phases and stock returns. Journal of Empirical Finance, 13(1), 1-23.

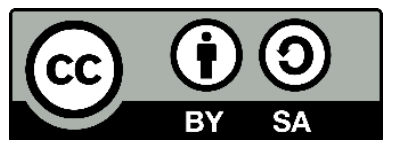

(C) 2019 by the authors. Licensee ACRN Publishing, Austria, Editor in Chief Prof. Dr. Othmar M. Lehner. This article is an open access article distributed under the terms and conditions of the Creative Commons Attribution (CC BY SA) license (https://creativecommons.org/licenses/by-sa/4.0/) 